\title{
THE EFFECT OF DIFFERENT LIGHT-CURING UNITS ON TENSILE STRENGTH AND MICROHARDNESS OF A COMPOSITE RESIN
}

\author{
Eduardo Batista FRANCO ${ }^{1}$, Patrícia Aleixo dos SANTOS ${ }^{2}$, Rafael Francisco Lia MONDELLI ${ }^{3}$
}

1- DDS, MSc, PhD, Associate Professor, Department of Endodontics, Dentistry and Dental Materials, Bauru School of Dentistry, São Paulo State University, Bauru, SP, Brazil.

2- DDS, MSc, Graduate Student, Department of Restorative Dentistry, Dental School of Araraquara, São Paulo State University, Araraquara, $S P$, Brazil.

3- DDS, MSc, PhD, Assistant Professor, Department of Endodontics, Dentistry and Dental Materials, Bauru School of Dentistry, São Paulo State University, Bauru, SP, Brazil.

Corresponding address: Eduardo Batista Franco - Departamento de Endodontia, Dentística e Materiais Dentários. - Faculdade de Odontologia de Bauru - USP - Al. Dr. Octávio Pinheiro Brisolla, 9-75 - 17012-901 - Bauru - SP, Brasil - Phone: 55-14 32358484 - e-mail: ebfranco@fob.usp.br

Received: May 5, 2006 - Modification: November 23, 2006 - Accepted: October 1, 2007

\begin{abstract}
$T$ 1 he aim of this study was to evaluate the influence of different light-curing units on the tensile bond strength and microhardness of a composite resin (Filtek Z250 - 3M/ESPE). Conventional halogen (Curing Light 2500 - 3M/ESPE; CL) and two blue light emitting diode curing units (Ultraled - Dabi/Atlante; UL; Ultrablue IS - DMC; UB3 and UB6) were selected for this study. Different light intensities (670, 130, 300, and $600 \mathrm{~mW} / \mathrm{cm}^{2}$, respectively) and different curing times (20s, 40s and 60s) were evaluated. Knoop microhardness test was performed in the area corresponding to the fractured region of the specimen. A total of 12 groups $(n=10)$ were established and the specimens were prepared using a stainless steel mold composed by two similar parts that contained a cone-shaped hole with two diameters $(8.0 \mathrm{~mm}$ and $5.0 \mathrm{~mm})$ and thickness of $1.0 \mathrm{~mm}$. Next, the specimens were loaded in tensile strength until fracture in a universal testing machine at a crosshead speed of $0.5 \mathrm{~mm} / \mathrm{min}$ and a $50 \mathrm{~kg}$ load cell. For the microhardness test, the same matrix was used to fabricate the specimens (12 groups; $\mathrm{n}=5$ ). Microhardness was determined on the surfaces that were not exposed to the light source, using a Shimadzu HMV-2 Microhardness Tester at a static load of $50 \mathrm{~g}$ for 30 seconds. Data were analyzed statistically by two-way ANOVA and Tukey's test ( $<<0.05)$. Regarding the individual performance of the light-curing units, there was similarity in tensile strength with 20-s and 40-s exposure times and higher tensile strength when a 60-s light-activation time was used. Regarding microhardness, the halogen lamp had higher results when compared to the LED units. For all light-curing units, the variation of light-exposure time did not affect composite microhardness. However, lower irradiances needed longer light-activation times to produce similar effect as that obtained with high-irradiance light-curing sources.
\end{abstract}

Uniterms: Photopolymerization; LED; Microhardness; Tensile strength.

\section{INTRODUCTION}

The properties of resin-based composites materials are frequently reevaluated because they may be influenced by several factors. It is known that degree of conversion is related to some properties, such as microhardness and intrinsic strength of the material depending on composite resin shade, curing time, light-curing unit, irradiance, emitted light spectrum and increment thickness ${ }^{3,5,8,9,14,17,21,23}$. On the other hand, incomplete polymerization may increase water sorption and solubility, adversely affecting the esthetics of the restoration ${ }^{5}$. In the material's region where curing is not effective, the possible consequences include postoperative sensitivity, microleakage and premature failure of the restoration ${ }^{4,15}$

Light emitting diodes (LEDs) produce a narrow band of wavelengths (450-490 nm) that is conveniently situated in the absorption spectrum of camphorquinone, which is the photoinitiator present in most light-activated dental materials. Therefore, no filters are required in LED lightcuring units (LCUs) ${ }^{11,16}$. This feature allows total use of the emitted light, resulting in minimal heat generation, differing from halogen curing units (QTH). Another difference between these light-curing units is their durability. While LEDs last for a thousands hours, conventional QTH light bulbs last for only 30 to 50 hours $^{12,17,25}$. The blue LEDs show greater conversion of monomer to polymer compared to halogen units, as the higher irradiance is coincident with 
camphorquinone peak of absorption ${ }^{6}$.

The first generation of LED curing units, which often contained multiple LEDs, had a relatively low power output. According to some authors ${ }^{10,22}$, these units may reach similar values of irradiance to those of conventional light sources. In contrast, a second-generation of LCUs has been developed using high-power light emitting diodes, which deliver a different spectral distribution with increased output. Compared to the first generation, the generation one offers better performance at shorter curing times.

With the introduction of high irradiance LED curing units, there was a need to investigate their polymerization potential varying the curing time. The analysis of composite surface hardness, alone, is not an adequate parameter to evaluate the depth of polymerization because the surface material will invariably polymerize, even with low power density light source. Therefore, the association of other mechanical tests would be more adequate to evaluate physical properties of post-polymerization restorative materials ${ }^{5}$.

Although there have been reports on differences in the effectiveness of LED LCUs compared to conventional halogen light sources, there is no comparative study addressing different light-curing sources and associating microhardness to cohesive strength.

The aim of this study was to evaluate the influence of different light-curing units on the tensile bond strength and microhardness of a composite resin.

\section{MATERIALAND METHODS}

Three LCUs were selected for this study. A conventional halogen source: Curing Light 2500 - CL (3M/ESPE; batch 3017518) with irradiance of $670 \mathrm{~mW} / \mathrm{cm}^{2}$ and two LED LCUs: Ultraled - UTL (Dabi/Atlante - batch 4505H000/6 n.001112) with irradiance of $130 \mathrm{~mW} / \mathrm{cm}^{2}$ and Ultrablue IS (DMC Equipments - batch 0144) with irradiance of $300 \mathrm{~mW} / \mathrm{cm}^{2}$ (UB3) and $600 \mathrm{~mW} / \mathrm{cm}^{2}$ (UB6). Power output was verified with a radiometer (Curing Radiometer Model 100P/N - 10503; Demetron Research Corp.) immediately before each photoactivation throughout the study.

Filtek Z250 (3M/ESPE - batch 4PE; shade A1) was the composite resin of choice. Twelve experimental groups $(n=10)$ were formed according to the variations of irradiance and exposure times (20, 40 and 60 seconds). Specimens were prepared using a stainless steel mold composed by two similar parts which contained a cone-shaped hole with two diameters $(8.0 \mathrm{~mm}$ and $5.0 \mathrm{~mm})$ and thickness of $1.0 \mathrm{~mm}$. Both parts of the mold were placed in contact by the smaller diameter. An acrylic base and a polyester strip were adapted below them. Then, the composite resin was inserted into both matrixes in a single increment using a plastic spatula. A polyester strip was placed on resin surface to allow an intimate contact with the light source. Light-activation was done according to with the exposure times established for each experimental group. To ensure adequate polymerization of each mold part, activation was a two-step procedure: specimens were cured half of the time with the light source at the top and half of the time at the bottom of the mold.

The specimens prepared for the microhardness test were similar to those used in the tensile strength test, except for the fact that a transparent strip was placed between the two parts of the matrix to guarantee appropriate smoothness at the interface corresponding to the material's union area, which was required to accurate assessment of microhardness.

Specimens were stored in a lightproof container for 10 minutes after polymerization and then submitted to tensile strength tests in a universal testing machine (Kratos - Model K2000MP, batch M970201) running at a crosshead speed of $0.5 \mathrm{~mm} / \mathrm{min}$ and using a $50 \mathrm{Kg}$ load cell until fracture. Values obtained in $\mathrm{kgf} / \mathrm{cm}^{2}$ were converted to MPa. Knoop microhardness tested in a Shimadzu HMV-2 Microhardness Tester (Shimadzu Corporation, Kyoto, Japan - batch 34404152-02 n.63034100673), at a static load of $50 \mathrm{~g}$ for 30 seconds, that was performed 10 minutes after specimen fabrication. Five random indentations were made at the center of the surface samples.

Data were submitted to two-way ANOVA and Tukey's test for individual comparisons. Significance level was set at $5 \%$.

\section{RESULTS}

Tensile bond strength means and standard deviation are given on Table 1.

No statistically significant differences were observed among the LCUs when 20-s and 40-s light-exposure times were used. However, when evaluating the light-exposure time of $60 \mathrm{~s}$, the tensile bond strength means obtained with UB6 (1.36 MPa) and UTL (1.18 MPa) were, respectively, statistically similar and superior to the others units (CL 0.94MPa and UB3 - 0.99MPa), which, in turn, showed did not differ significantly to each other.

Data on Table 2 show that the conventional LCU (CL) had higher microhardness means than the other LCUs, which were $72.10 \mathrm{KHN}$ with 60-s light-exposure time, 68.44 KHN for $40 \mathrm{~s}$ and $61.12 \mathrm{KHN}$ for $20 \mathrm{~s}$. Regarding the LED units, UTL showed a better behavior with 60-s light-exposure time, which was similar to that of UB3 and UB6 for the same time of photoactivation. To Ultrablue IS, it was verified that, at $300 \mathrm{~mW} / \mathrm{cm}^{2}$ of light intensity, the performance was similar for all exposure times, implying that there was no statistically significant difference among the microhardness means among the experimental condition (55.37 KHN, 54.06 KHN and $57.36 \mathrm{KHN}$ for $20 \mathrm{~s}, 40 \mathrm{~s}$ and $60 \mathrm{~s}$, respectively). UB6 had similar microhardness means with either 40 -s or 60 -s light-exposure times (53.85 KHN and 53.66 KHN).

\section{DISCUSSION}

It is known that irradiance has great influence on material's polymerization. However, the energy dose is considered the most important factor on extension of the 
degree of conversion. In this study, it was observed that there was lower microhardness when a low-irradiance LCU (UTL $-130 \mathrm{~mW} / \mathrm{cm}^{2}$ ) was used with a light-exposure of $20 \mathrm{~s}$ (energy density - $2.6 \mathrm{~J} / \mathrm{cm}^{2}$ ) (Table 2). Nevertheless, these data were not found when the light-exposure time increased to $40 \mathrm{~s}$ and $60 \mathrm{~s}$, which may be explained by the higher energy density produced. In accordance to this, the use of an established energy dose has to be determined to lowirradiance units that may promote similar mechanical properties to material as the medium or high-irradiance ones.

In the present study, different energy doses were used, so that the energy allowing the best performance at these experimental conditions would be defined, according to combinations of irradiance and light exposure time. The values of energy dose produced when the halogen LCU (CL) was used were $13.4 \mathrm{~J} / \mathrm{cm}^{2}, 26.8 \mathrm{~J} / \mathrm{cm}^{2}$ and $40.2 \mathrm{~J} / \mathrm{cm}^{2}$ for the activation times of $20 \mathrm{~s}, 40 \mathrm{~s}$ and $60 \mathrm{~s}$, respectively, and in this case, the composite resin reached appropriated cohesive strength and microhardness. Regarding the irradiance the LED unit (UTL), the maximum energy provided

TABLE 1- Composite resin tensile bond strength means (MPa) and standard deviation

\begin{tabular}{lll}
\hline $\begin{array}{l}\text { Light-curing } \\
\text { units }\end{array}$ & Curing times & Means $( \pm$ SD) \\
\hline CL & & \\
CL & $20 \mathrm{~s}$ & $0.98 \mathrm{abc}( \pm 0.29)$ \\
$\mathrm{CL}$ & $40 \mathrm{~s}$ & $1.02 \mathrm{abc}( \pm 0.22)$ \\
UTL & $60 \mathrm{~s}$ & $0.94 \mathrm{ab}( \pm 0.13)$ \\
UTL & $20 \mathrm{~s}$ & $0.99 \mathrm{ab}( \pm 0.11)$ \\
UTL & $40 \mathrm{~s}$ & $0.97 \mathrm{ab}( \pm 0.18)$ \\
UB3 & $60 \mathrm{~s}$ & $1.18 \mathrm{bc}( \pm 0.26)$ \\
UB3 & $20 \mathrm{~s}$ & $0.87 \mathrm{a}( \pm 0.17)$ \\
UB3 & $40 \mathrm{~s}$ & $1.05 \mathrm{abc}( \pm 0.24)$ \\
UB6 & $60 \mathrm{~s}$ & $0.99 \mathrm{ab}( \pm 0.19)$ \\
UB6 & $20 \mathrm{~s}$ & $1.02 \mathrm{abc}( \pm 0.22)$ \\
UB6 & $40 \mathrm{~s}$ & $1.02 \mathrm{abc}( \pm 0.18)$ \\
\hline
\end{tabular}

Different letters indicate statistically significant difference at $5 \%$. was of $7.8 \mathrm{~J} / \mathrm{cm}^{2}$ when light exposure time was $60 \mathrm{~s}$. UB3 showed similar performance to UTL, with a light-exposure time of $20 \mathrm{~s}$, even though the total energy was inferior to that one considered minimum to complete cure of the material $\left(12 \mathrm{~J} / \mathrm{cm}^{2}\right)^{2,26}$. When light-exposure times were longer (40 s and $60 \mathrm{~s}$ ) and irradiance was $600 \mathrm{~mW} / \mathrm{cm}^{2}$ (UB6), the energy was maintained at a level considered as satisfactory (12 to $\left.36 \mathrm{~J} / \mathrm{cm}^{2}\right)^{2,7,26}$. This procedure guaranteed that material polymerization reached values that configure appropriated monomer conversion.

All groups polymerized with the halogen LCU (CL) had a good behavior in relation to hardness. This fact might be associated to a higher heat generation by this unit, which may speed up the polymer chain induction process in composite resins. This may increase the mobility of molecules during the reaction and allows that more monomers react before the curing process ends, considering, mainly, the short exposure ${ }^{13}$.

The use of low-power density or low-irradiance LCUs allows obtaining better marginal adaptation of resin-based composites through slow polymerization. Previous studies $^{11,24}$ have reported that a low degree of conversion permits flow of material, decreases shrinkage stress, and conducts to a better marginal adaptation. In this way, a well succeeded composite resin restoration depends on the association of low rate shrinkage, good flowability, appropriate cure and satisfactory mechanical properties.

In this study, the halogen LCU (CL) was adopted as a control to compare its performance to that of other LCUs. This LCU has the highest irradiance $\left(670 \mathrm{~mW} / \mathrm{cm}^{2}\right)$ presenting a different behavior of composite resin in comparison to LEDs, related to the tensile strength as well as to the microhardness. The first-generation LED unit (Ultraled - Dabi/Atlante) with low power density (130 mW/ $\mathrm{cm}^{2}$ ) had a good tensile strength performance with material thickness of $1 \mathrm{~mm}$ and longer activation times. This can be observed in Table 1 with the 60-s exposure time. In addition, the Ultrablue IS (DMC) unit, which can be used in two different power densities (300 and $600 \mathrm{~mW} / \mathrm{cm}^{2}$ ), showed a similar behavior to that of the halogen lamp in both conditions, suggesting that similar degree of conversion was reached with both equipments. A recent study ${ }^{1}$ reported obtained similar data when a conventional halogen unit was compared with an intermediate irradiance LED unit. This might be explained due the better use of the energy emitted by the LED unit, with light in one spectral wavelength

TABLE 2- Composite resin microhardness means (KHN) and standard deviation Light-curing unit

\begin{tabular}{llll}
\hline Light-curing unit & Means $(\mathbf{t}=\mathbf{2 0} \mathrm{s})$ & Means $(\mathrm{t}=\mathbf{4 0} \mathrm{s})$ & Means $(\mathrm{t}=\mathbf{6 0} \mathrm{s})$ \\
\hline CL & $61.12 \pm 8.66 \mathrm{fg}$ & $68.44 \pm 3,03 \mathrm{gh}$ & $72.10 \pm 5.34 \mathrm{~h}$ \\
UTL & $38.86 \pm 4.68 \mathrm{a}$ & $45.98 \pm 4,69 \mathrm{a} \mathrm{b}$ & $55.06 \pm 5.35 \mathrm{bc}$ \\
UB3 & $55.37 \pm 2.91 \mathrm{c}$ & $54.06 \pm 4,30 \mathrm{c}$ & $57.36 \pm 4.43 \mathrm{c}$ \\
UB6 & $45.22 \pm 1.36 \mathrm{~cd}$ & $53.85 \pm 1,87 \mathrm{ef}$ & $53.66 \pm 3.67 \mathrm{e}$ \\
\hline
\end{tabular}

Different letters indicate statistically significant difference at $5 \%$. 
coincidently to absorption spectrum of camphorquinone, being absorbed by the photoinitiator that composes the material.

It has been stated ${ }^{20}$ that microhardness testing is an excellent tool to determine when a composite resin is appropriately cured. Some authors believe that when microhardness at the bottom of a 1-mm-thick composite resin specimen is about $80-90 \%$ of its superficial microhardness, it indicates a great degree of polymerization ${ }^{18,27}$. Accordingly, in the present study, some microhardness values did not exceed $20 \%$ of decrease when each experimental condition (time x power density) was analyzed alone. The maximum microhardness value was obtained with CL (72.10KHN) at 60-s light-exposure time. Comparing the values, it was noted that UB3 reached $90.6 \%$ of microhardness when composite resin was cured for $20 \mathrm{~s}$, showing that its degree of polymerization was satisfactory. However, the proportion in the other groups was lower than $80 \%$, which means that the polymerization was not ideal. At $40 \mathrm{~s}$ of activation time, both power densities of Ultrablue IS (UB3 and UB6) showed sufficient microhardness values (above 80\%) when compared to CL. Finally, values found for 60-s light-exposure with UTL and UB3 units were similar to those found for light-activation with CL (76.4\% and 79.9\%), but the other groups did not reach satisfactory microhardness values.

Figure 1 correlates, microhardness and tensile strength and the different LCUs and power densities are presented and coded. This figure depicts the effect of LCU power density and exposure length. These data indicate that composite tensile strength was maximized by all LCUs. However, hardness values increased with increasing exposure duration. This result indicates that maybe the tensile strength is related to some critical flaw, which is not dependent on the manner in which or extent to which the polymer network forms.
Therefore, it should be considered that, when a composite resin restoration does not receive sufficient amount of energy with an appropriate wavelength provided by the LCU,, the effects on wearing may be higher and increase the deterioration of the restoration margins and also decrease the tooth-material adhesive strength, microhardness and Young modulus. As a consequence, dentists must use LCUs that allow high doses with correct wavelength for polymerization ${ }^{19}$. Furthermore, a defined parameter for clinical practice has not yet been established. Thus, it is necessary to emphasize the importance of consulting the manufacturer's information on product label to verity the energy density that is necessary to provide an adequate polymerization of the specific product. So far, a consensus has not been reached in the literature regarding a single value that would be applicable to all commercially available materials because each product has its own particularities.

LED technology may be effectively employed on polymerization of resin materials, including low-irradiance units, as long as some principles of use are respected. Overall, it is important to know the irradiance of the LCU and the material's curing time, according to the total dose recommended by the manufacturer. It is also important not to exceed the recommended increment thickness, in such a way that the light source can obtain the same performance as that of conventional halogen lamps.

\section{CONCLUSIONS}

It may be concluded that: 1) Regarding the individual performance of the tested light-curing units, there was similar tensile strength for both light-exposure times of 20 and 40 seconds. However, at 60 seconds, the units with higher

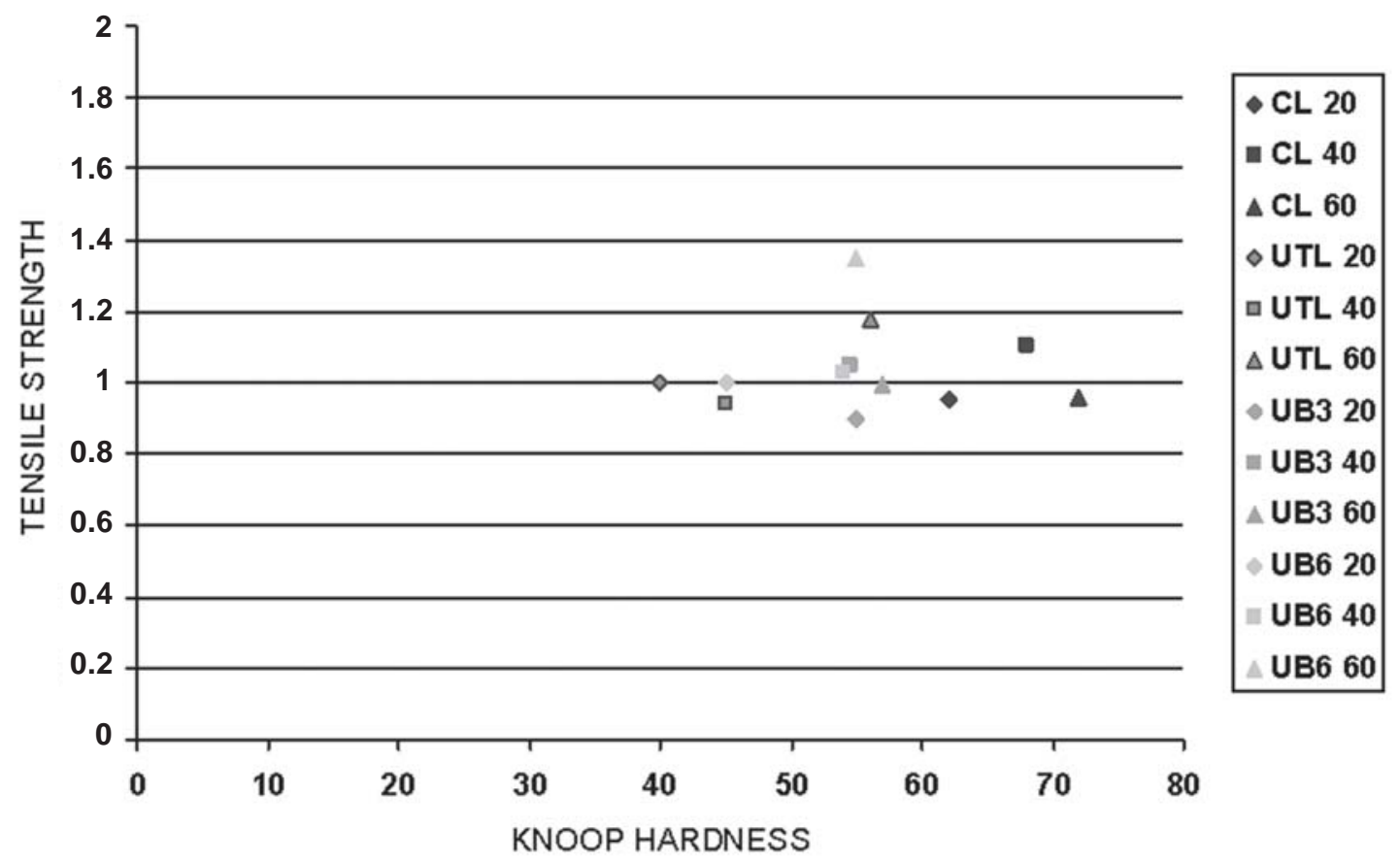

FIGURE 1- Correlation between microhardness $(\mathrm{KNH})$ and tensile strength $(\mathrm{MPa})$ means obtained with the tested material 
power density (CL and UB6) showed better results; 2) The halogen light-curing unit had better results than the LED units. The variation of exposure time did not have any influence on the interfacial microhardness comparing the different types of light-curing units. However, it was evident that units with lower power density need a longer activation time to produce a similar effect as that of light sources with high power density.

\section{ACKNOWLEDGMENTS} 2003-7

This study was supported by CNPq - grant n. 130607/

\section{REFERENCES}

1- Bala O, Ölmez A, Kalayci S. Effect of LED and halogen light curing on polymerization of resin-based composites. J Oral Rehab. 2005;32(2):134-40.

2- Calheiros FC, Braga R R, Kawano Y; Ballester RY. Relationship between contraction stress and degree of conversion in restorative composites. In: Academy of Dental Materials; 2004, Genebra. International ADM - Academy of Dental Materials, 2004. v. 18

3- Caughman WF, Rueggeberg FA, Curtis Junior JW. Clinical guidelines for photocuring restorative resins. J Am Dent Assoc. 1995;126(9):1280-6.

4- Davidson-Kaban SS et al. The effect of curing light variation on bulk curing and wall-to-wall quality of two types and various shades of resin composites. Dent Mater. 1997;13:344-52.

5- Dunne SM, Davies BR, Millar BJ. A survey of the effectiveness of dental light-curing units and comparison of light testing devices. $\mathrm{Br}$ Dent J. 1996;180(1):411-6.

6- Fujibayashi K, Ishimaru K, Takahashi N, Kohno A. Newly developed curing unit using blue light-emitting diodes. Dent Jpn. 1998;34:4953.

7- Halvorson RH, Erickson RL, Davidson CL. An energy conversion relationship predictive of conversion profiles and depth of cure for resin-based composite. Oper Dent. 2003;28(3):307-14.

8- Hansen EK, Asmussen E. Visible-light curing units: correlation between depth of cure and distance between exit window and resin surface. Acta Odontol Scand. 1997;55(3):162-6.

9- Harrington E, Wilson HJ, Shortall AC. Light-activated restorative materials: a method of determining effective radiation times. J Oral Rehabil. 1996;23(3):210-8.

10- Jandt KD, Mills RW, Blackwell GB, Ashworth SH. Depth of cure and compressive strength of dental composites cured with blue light emitting diodes (LEDs). Dent Mater. 2000;16(1):41-7.

11- Koran P, Kürschner R. Effect of sequential versus continuous irradiation of a light-cured resin composite on shrinkage, viscosity, adhesion, and degree of polymerization. Am J Dent. 1998;11(1):1722 .

12- Kurachi C, Tuboy AM, Magalhães DV, Bagnato VS. Hardness evaluation of dental composite polymerized with experimental LEDbased devices. Dent Mater. 2001;17(4):309-15.
13- Lovell LG, Lu H, Elliott JE, Stansbury JW, Bowman CN. The effect of cure rate on the mechanical properties of dental resins. Dent Mater. 2001;17(6):504-11.

14- Martin FE. A survey of the efficiency of visible light curing units. J Dent. 1998;26(3):239-43.

15- Mehl A, Hickel R, Kunzelmann KH. Physical properties and gap formation of light-cured composites with and without 'softstartpolymerization’. J Dent. 1997;25(3/4):321-30.

16- Mills RW, Jandt KD, Ashworth SH. Dental composite depth of cure with halogen and blue light emitting diode technology. Brit Dent J. 1999;186(8):388-91.

17- Nomoto R. Effect of light wavelength on polymerization of light-cured resins. Dent Mater J. 1997;16(1):60-73.

18- Pilo R, Cardash HS. Post-irradiation polymerization of different anterior and posterior visible light-activated resin composites. Dent Mater. 1992;8(5):299-304.

19- Price RBT, Felix CA, Andreou P. Evaluation of a secondgeneration LED curing light. J Can Dent Assoc. 2003; 69(10):666666h.

20- Price RBT, Felix CA, Andreou P. Effects of resin composite composition and irradiation distance on the performance of curing lights. Biomaterials. 2004;25(18):4465-77.

21-Rueggeberg FA, Jordan DM. Effect of light tip distance on polymerization of resin composite. Int J Prosthodont. 1993;6(4):36470 .

22- Rueggeberg FA, Caughman WF, Curtis JW. Effect of light intensity and exposure duration on cure of resin composite. Oper Dent. 1994;19(1):26-32.

23- Turbino ML, Vinha D, Centola AL, Campos GM. Photopolymerized resins: surface hardness variation in relation to time of polymerization and setting. Braz Dent J. 1992;3(2):87-95.

24- Uhl A, Mills RW, Jandt KD. Polymerization and light-induced heat of dental composites cured with LED and halogen technology. Biomaterials. 2003;24(10):1809-20.

25- Whitters CJ, Girkin JM, Carey JJ. Curing of dental composites by use of InGaN light-emitting diodes. Optics Letters. 1999;24(1):678.

26- Yap AUJ, Severatne C. Influence of light energy density on effectiveness of composite cure. Oper Dent. 2001;26(5):460-6.

27- Yearn JA, Macclesfiled UK. Factors affecting cure of visible light activated composites. Int Dent J. 1985;35(3):218-5. 